\title{
Supplementary Information:
}

\section{Strategy on Persisting in Distinct Activity of Plasmon-Activated Water}

Chih-Ping Yang, ${ }^{1}$ Hui-Yen Tsai, ${ }^{1}$ Ching-Li Tseng, ${ }^{2}$ Pei-Jun Hao, ${ }^{3}$ Yu-Chuan Liu ${ }^{1,4 *}$

${ }^{1}$ Department of Biochemistry and Molecular Cell Biology, School of Medicine,

College of Medicine, Taipei Medical University, No. 250, Wuxing St., Taipei 11031,

Taiwan

${ }^{2}$ Graduate Institute of Biomedical Materials and Tissue Engineering, College of

Biomedical Engineering, Taipei Medical University, 250 Wuxing St., Taipei 11031,

Taiwan

${ }^{3}$ Graduate Institute of Medical Science, College of Medicine, Taipei Medical

University, 250 Wuxing St., Taipei 11031, Taiwan

${ }^{4}$ Cell Physiology and Molecular Image Research Center, Wan Fang Hospital, Taipei

Medical University

*Address correspondence to: 1iuyc@tmu.edu.tw 


\section{MATERIALS AND METHODS}

Preparation of Plasmon-Activated Water (PAW). The preparation conditions were previously reported. ${ }^{1}$ In a typical preparation, deionized (DI) water ( $\mathrm{pH}$ 7.02, temperature of $24.3^{\circ} \mathrm{C}$ ) flowed through a glass tube filled with gold nanoparticles (AuNPs) adsorbed onto ceramic particles under illumination with green light-emitting diodes (LEDs, with a wavelength maximum centered at $530 \mathrm{~nm}$ ). Then the PAW (pH 7.02 , temperature of $24.3^{\circ} \mathrm{C}$ ) was collected in capped glass sample bottles for subsequent use and measurements within $2 \mathrm{~h}$. To further examine the purity of the prepared PAW, inductively coupled plasma-mass spectrometric (ICP-MS) analyses indicated that the concentrations of the slightly dissolved metals in the PAW based on a previous method ${ }^{1}$ were ca. $0.59 \mathrm{ppb}$ for $\mathrm{Au}, 43 \mathrm{ppb}$ for $\mathrm{Na}, 25 \mathrm{ppb}$ for $\mathrm{K}, 36 \mathrm{ppb}$ for $\mathrm{Al}, 13 \mathrm{ppb}$ for $\mathrm{Mg}, 2.9 \mathrm{ppb}$ for $\mathrm{Ca}$, and $0.68 \mathrm{ppb}$ for $\mathrm{Fe}$. Excluding $\mathrm{Au}$, the total equivalent molar concentration of these dissolved metals was equal to ca. $7.8 \times 10^{-6} \mathrm{~N}$. The measured value was ca. $6.9 \times 10^{-7} \mathrm{~N}$ for DI water as a reference.

Freezing Process of PAW in Ambient Laboratory Air. As-prepared samples of PAW were placed in refrigerators at different temperatures of ca. -20 (called slowly frozen PAW) and $-80{ }^{\circ} \mathrm{C}$ (called rapidly frozen PAW) for freezing PAW to ice. Also, as-prepared samples of PAW were placed in a liquid nitrogen system at ca. $-200{ }^{\circ} \mathrm{C}$ for completely freezing PAW to ice (called super-rapidly frozen PAW).

Melting Process of Frozen PAW in Ambient Laboratory Air. Before measuring the liquid properties of the treated PAW, samples of frozen PAW were rapidly melted to room temperature in a warm-water bath at $40{ }^{\circ} \mathrm{C}$ (called rapidly melted PAW). Another method for slowly melting frozen PAW to room temperature was to place the frozen PAW in ambient laboratory air (called slowly melted PAW). It took ca. $2 \mathrm{~h}$.

\section{Evaporation Rates of As-Prepared and Melted PAW at Room Temperature} into Ambient Laboratory Air. In these experiments, $10-\mathrm{mL}$ samples of as-prepared and melted PAW, and DI water were added to open glass sample bottles $(20 \mathrm{~mL})$, which were placed on a platform of an orbital shaker, operating at $150 \mathrm{rpm}$. The weight of each glass sample bottle was measured at $0.5,1$, and $2 \mathrm{~h}$ to determine the evaporated mass (g) of PAW and DI water. In these experiments, the relative humidity (RH) was ca. 50\%. Replicate measurements based on three similar samples were performed. The errors were obtained from the relative standard deviation (RSD).

Measurement of Zeta Potential of Water. Zeta potentials of water samples 
$(600 \mu \mathrm{L})$ were analyzed using a Malvern Zetasizer Nano ZS zeta potential analyzer. To avoid the influence of bacteria on the zeta potential during storage, samples were filtered through a $0.22-\mu \mathrm{m}$-pore membrane to remove bacteria. Filtered water was divided into three parts ( $n=3$ for each measurement). Parafilm-sealed samples were placed in a dark atmosphere before the measurement.

\section{Measurement of Free Radicals by Electron Spin Resonance (ESR)} Spectroscopy. A Bruker EMX ESR spectrometer was used for ESR measurements. ESR spectra were recorded at room temperature using a quartz flat cell designed for solutions. The dead times between sample preparation and ESR analysis after the last addition were exactly 1.5 and $10 \mathrm{~min}$ for experiments on hydroxyl and 2,2-diphenyl-1-picrylhydrazyl (DPPH) free radicals, respectively. Conditions of ESR spectrometry were as follows: $20 \mathrm{~mW}$ power at $9.78 \mathrm{GHz}$, with a scan range of $100 \mathrm{G}$ and a receiver gain of $6.32 \times 10^{4}$.

Sample Preparation for Measuring Hydroxyl Free Radicals. Hydroxyl free radicals were obtained using the well-known Fenton reaction, in which ferrous iron donates an electron to hydrogen peroxide to produce the hydroxyl free radical., ${ }^{2,3}$ Because the hydroxyl free radicals so produced are very unstable, they were [capped/captured?] by spin-trapping using 5,5-dimethyl-1-pyrroline N-oxide (DMPO) to form more-stable complex radicals for exact detection. Sample preparation is described as follows. First, $140 \mu \mathrm{L}$ of DI water or PAW was added to a microtube (Eppendorf). Then $20 \mu \mathrm{L}$ PBS (10x) was added to the tube. A complex of EDTA-chelated iron(II) was prepared by mixing equal volumes of $0.5 \mathrm{mM}$ iron(II), chloride tetrahydrate, and $0.5 \mathrm{mM}$ EDTA. Subsequently, $20 \mu \mathrm{L}$ EDTA-chelated iron(II) $(0.25 \mathrm{mM}), 10 \mu \mathrm{L} \mathrm{H}_{2} \mathrm{O}_{2}(0.2 \mathrm{mM})$, and $10 \mu \mathrm{L}$ DMPO (2 M) were sequentially added to the tube. The final volume in the tube was $200 \mu \mathrm{L}$. Exactly $1.5 \mathrm{~min}$ after the addition of DMPO, the ESR analysis was performed. To obtain an ESR spectrum, a sample was scanned for ca. $1.5 \mathrm{~min}$, accumulated eight times, and all signals were averaged.

Sample Preparation for Measuring DPPH Free Radicals. Compared to hydroxyl free radicals, DPPH is a kind of stable free radical. Sample preparation is described as follows. DPPH was dissolved in methanol to prepare a $4 \mathrm{mM}$ DPPH solution. Then the prepared DPPH solution and DI water or PAW was mixed $(100 \mu \mathrm{L}$ each) in a microtube. The final concentration of DPPH in the solution was $2 \mathrm{mM}$. Exactly 10 min after mixing the DPPH and water, the ESR analysis was performed. To measure an ESR spectrum, a sample was scanned one time (for ca. $42 \mathrm{~s}$ ). 
Oxygen Evolution Reaction (OER) Measurements. Typically, the oxygen evolution reaction was performed by a linear sweep voltammetry in a three-electrode system consisting of a bar Pt electrode $\left(0.07 \mathrm{~cm}^{2}\right)$, a Pt sheet and an $\mathrm{Ag} / \mathrm{AgCl}$ as the working, counter and reference electrodes, respectively. The corresponding electrochemical measurement was performed in $50 \mathrm{~mL}$ deoxygenated solution with $0.1 \mathrm{~N} \mathrm{KCl}$ at a scan rate of $0.05 \mathrm{~V} \mathrm{~s}^{-1}$, and was controlled with a potentiostat (model PGSTAT30, Eco Chemie).

\section{REFERENCES}

1. Chen, H. C.; Hwang, B. J.; Mai, F. D.; Liu, Y. C.; Lin, C. M.; Kuo, H. S.; Chou, D. S.; Lee, M. J.; Yang, K. H., Yu, C. C. et al. Active and Stable Liquid Water Innovatively Prepared Using Resonantly Illuminated Gold Nanoparticles. ACS Nano, 2014, 8, 2704-2713.

2. Ohsawa, I.; Ishikawa, M.; Takahashi, K.; Watanabe, M.; Nishimaki, K.; Yamagata, K.; Katsura, K.; Katayama, Y.; Asoh, S.; Ohta, S. Hydrogen Acts as A Therapeutic Antioxidant by Selectively Reducing Cytotoxic Oxygen Radicals. Nat. Med. 2007, 13, 688-694.

3. Liu, Y.; Imlay, J. A. Cell Death from Antibiotics without the Involvement of Reactive Oxygen Species. Science 2013, 339, 1210-1213. 


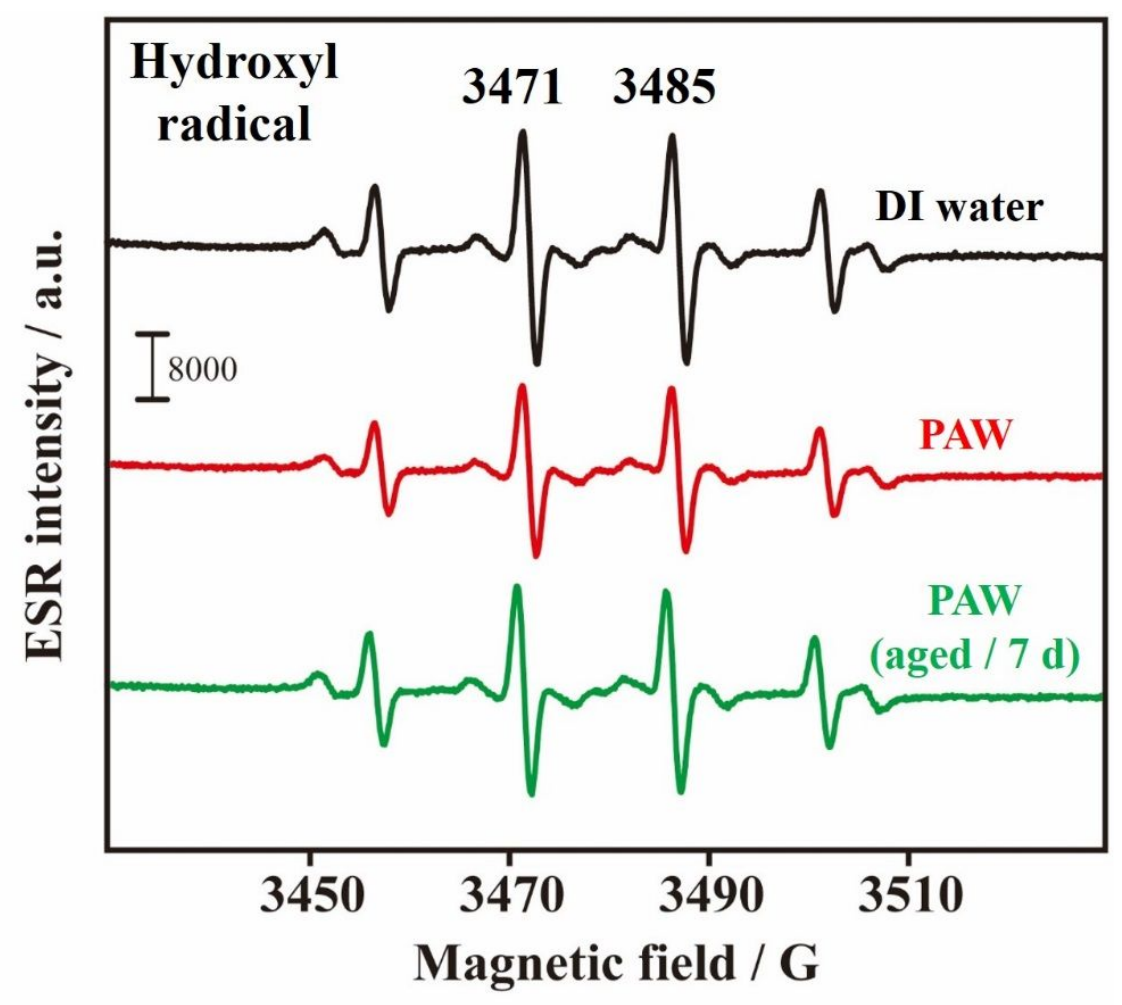

(A)

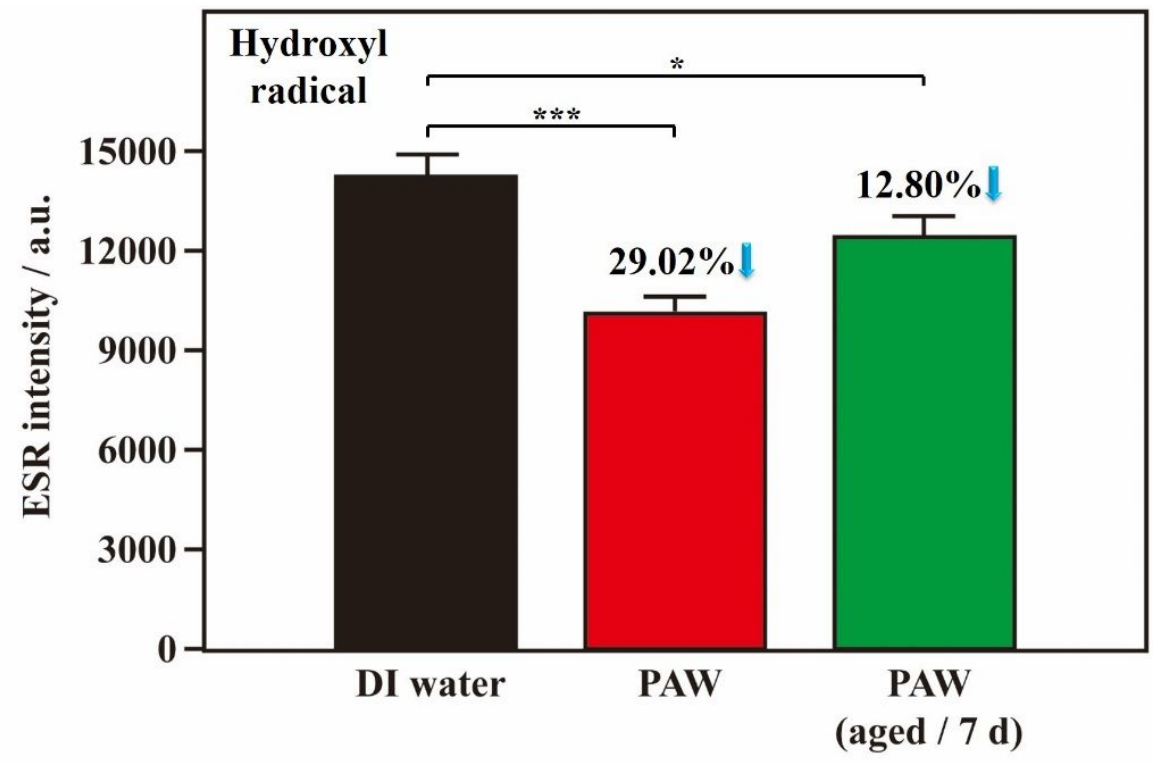

(B)

Figure S1. ESR spectra of hydroxyl free radicals based on as-prepared plasmon-activated water (PAW) (red), 7-day-aged liquid PAW (green) in a dark atmosphere, and deionized (DI) water (black) for reference. (A) Original spectra. (B) 
Statistical results. $* p<0.05 ; * * * p<0.001$.

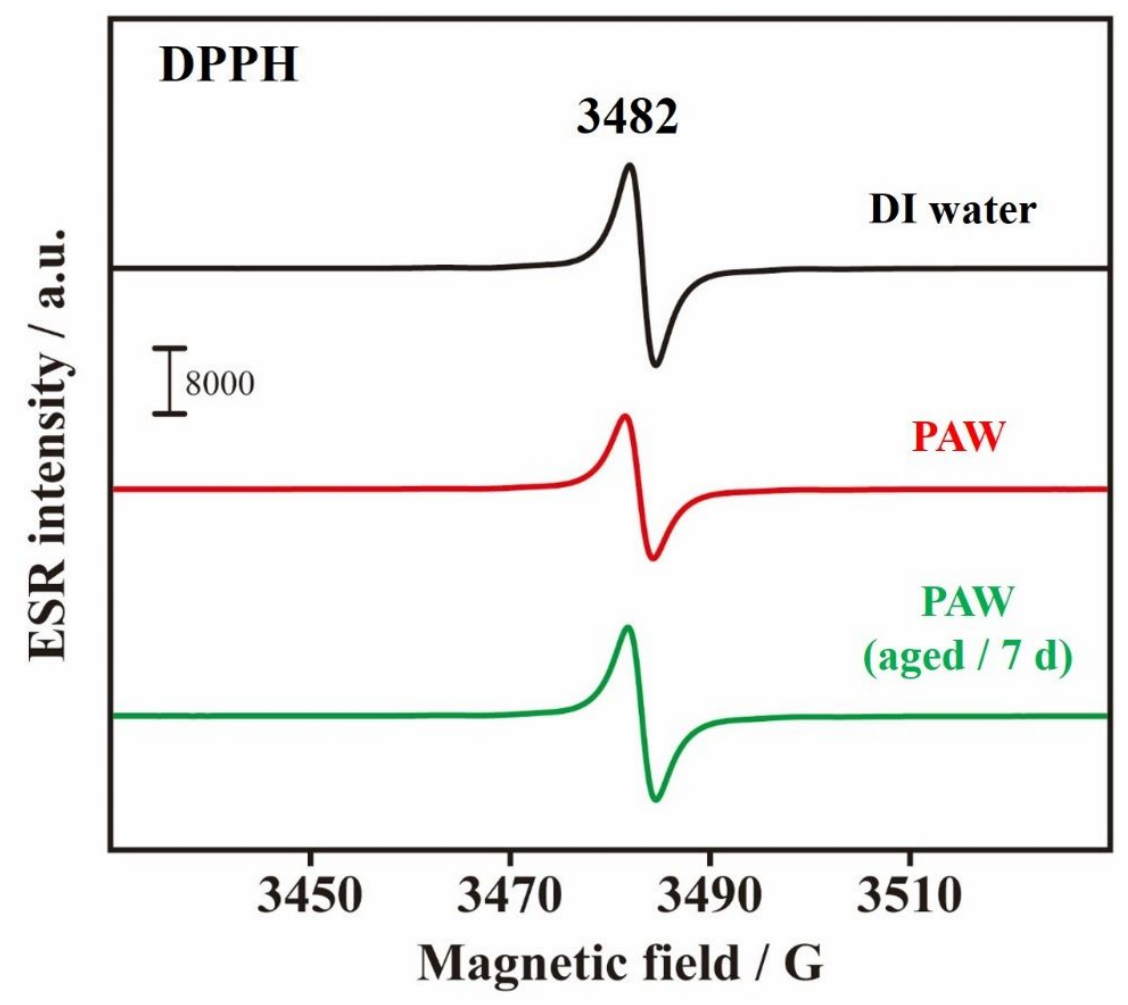

(A)

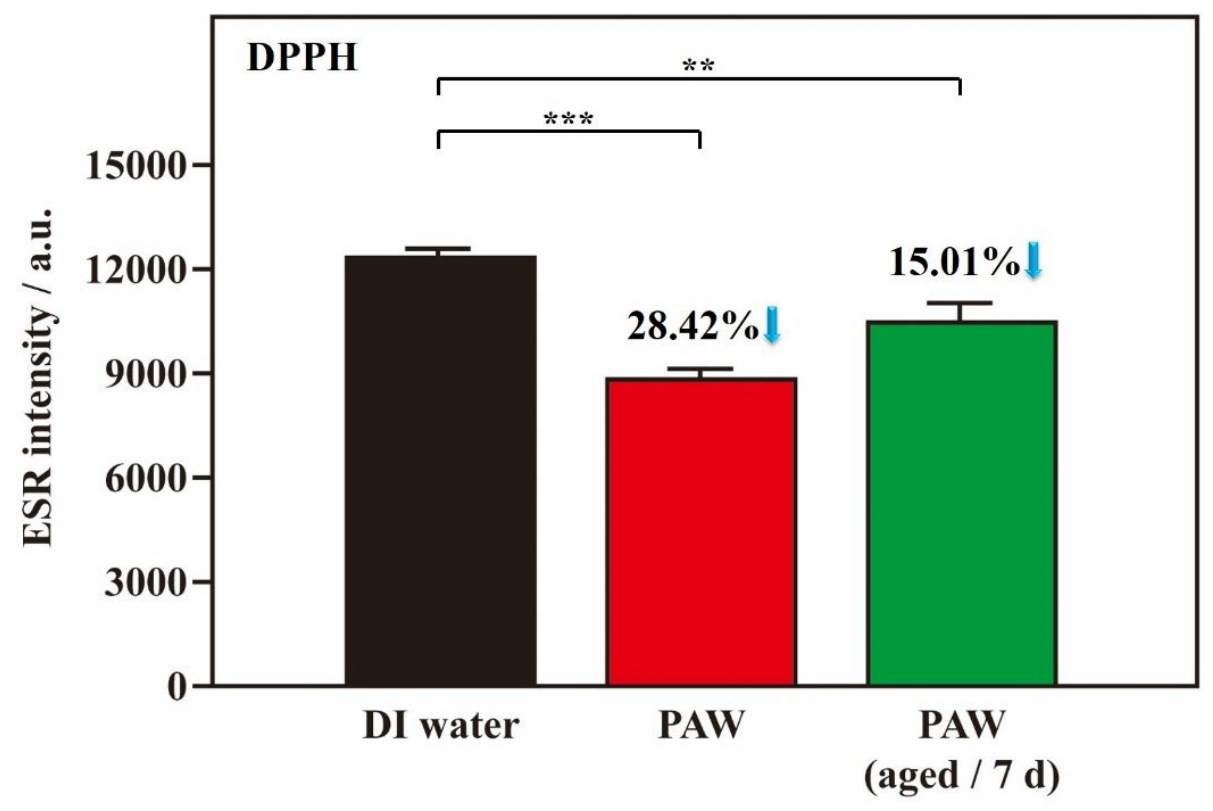

(B)

Figure S2. ESR spectra of DPPH free radicals based on as-prepared plasmon-activated water (PAW) (red), 7-day-aged liquid PAW (green) in a dark atmosphere, and deionized (DI) water (black) for reference. (A) Original spectra. (B) 
Statistical results. $* * p<0.01 ; * * * p<0.001$.

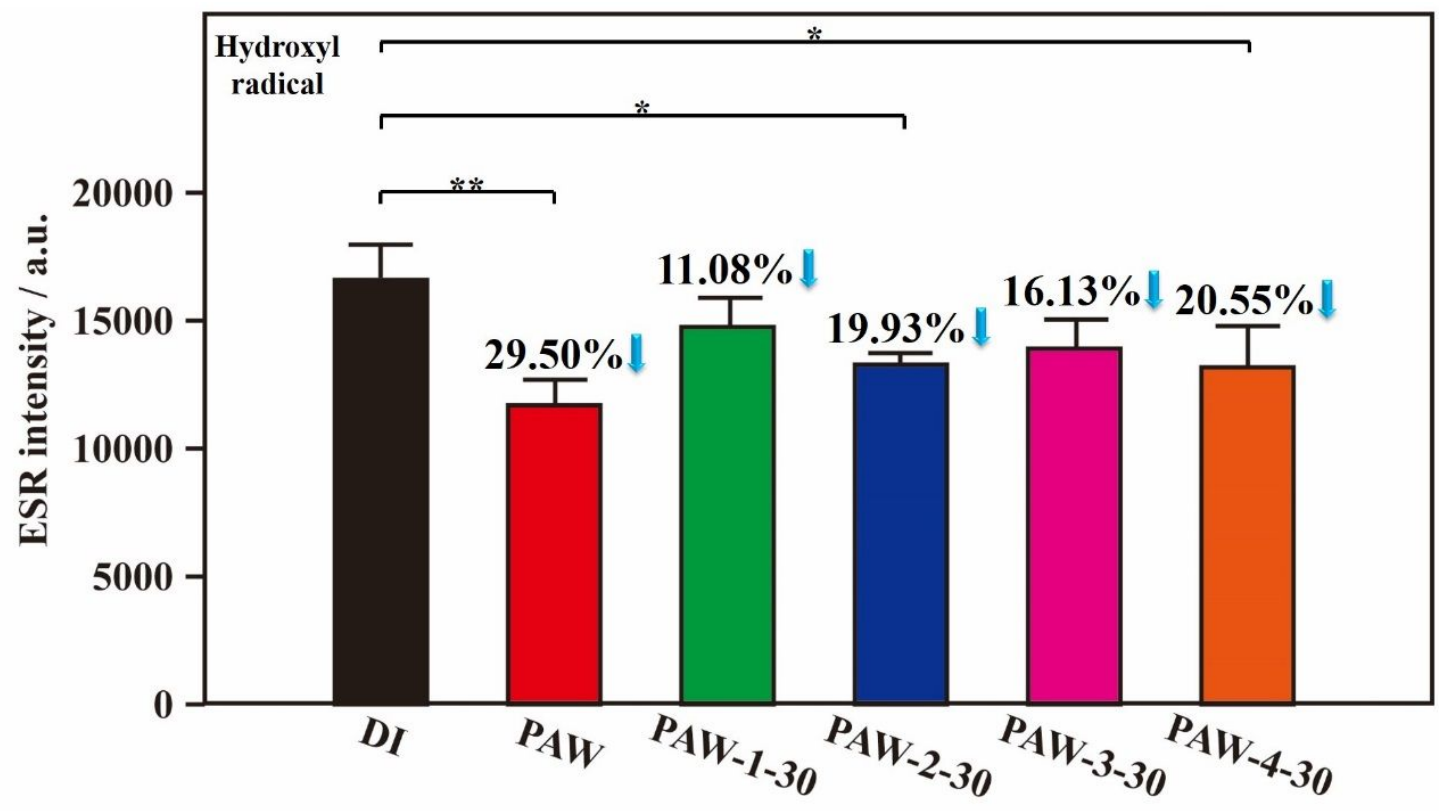

(A)

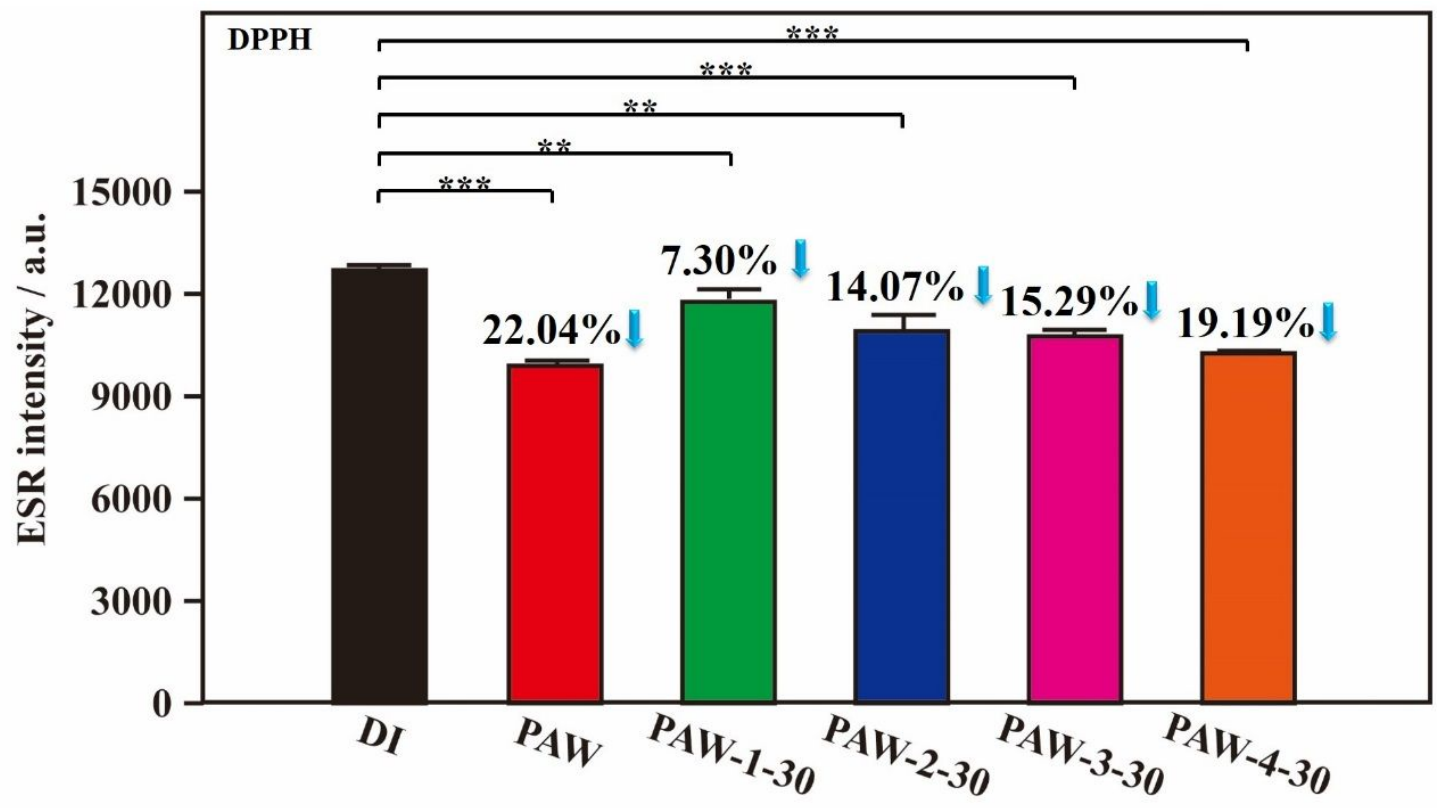

(B)

Figure S3. Statistical results of ESR spectra of hydroxyl and DPPH free radicals based on as-prepared plasmon-activated water (PAW; red), various 30-day-aged PAW, and deionized (DI) water (black) for reference. (A) Hydroxyl free radicals. (B) DPPH free radicals. Green: slowly frozen/slowly melted PAW-1-30; blue: slowly frozen/rapidly 
melted PAW-2-30; pink: rapidly frozen/slowly melted PAW-3-30; orange: rapidly frozen/rapidly melted PAW-4-30. ${ }^{*} p<0.05 ; * * p<0.01 ; * * * p<0.001$.

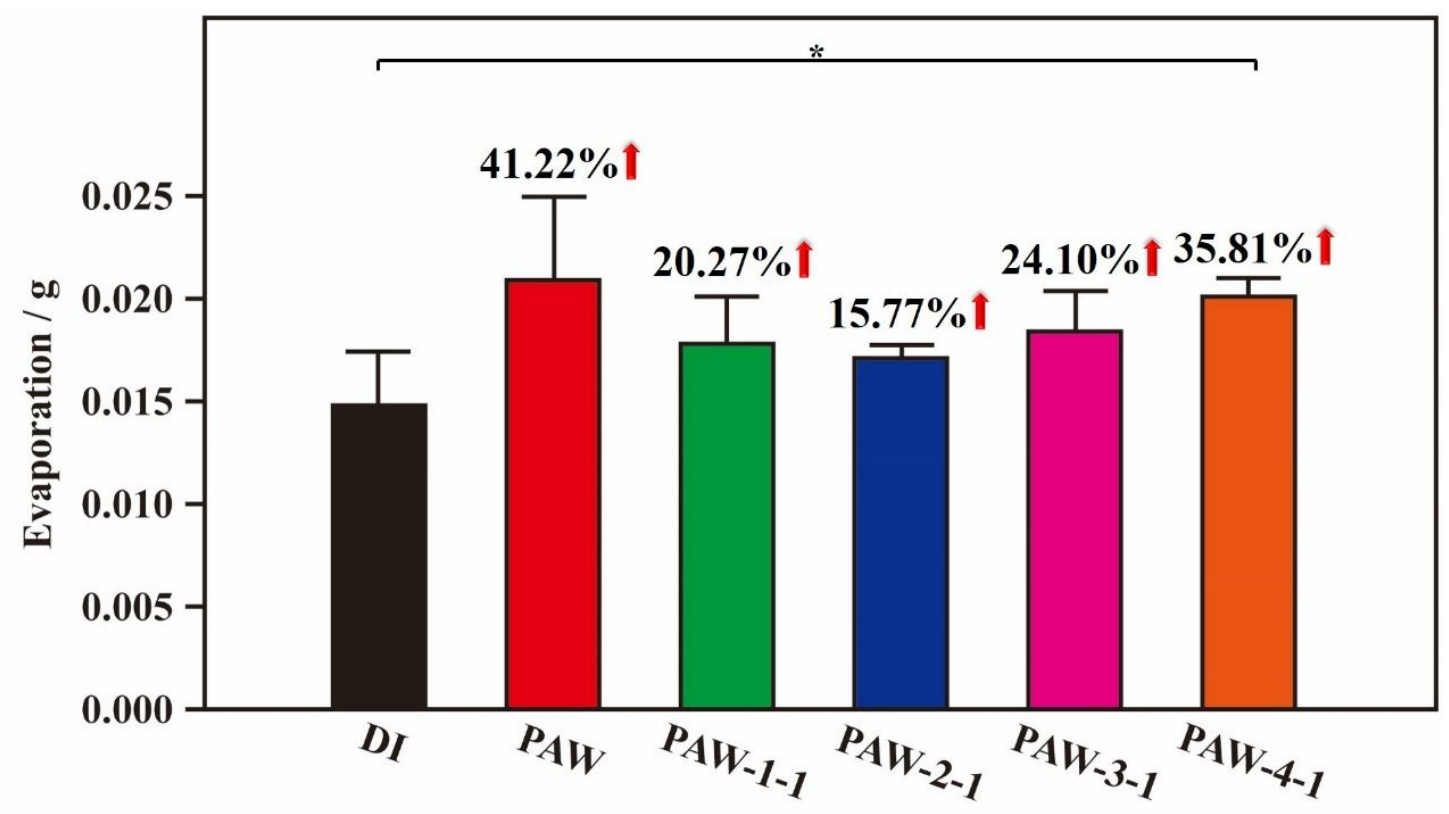

Figure S4. Evaporation quantities (g) after $0.5 \mathrm{~h}$ of as-prepared plasmon-activated water (PAW; red), various 1-day-aged PAW, and deionized (DI) water (black) for reference. Green: slowly frozen/slowly melted PAW-1-1; blue: slowly frozen/rapidly melted PAW-2-1; pink: rapidly frozen/slowly melted PAW-3-1; orange: rapidly frozen/rapidly melted PAW-4-1. * $p<0.05$. The evaporation experiments were performed at $1 \mathrm{~atm}, 24.3^{\circ} \mathrm{C}$, and $57.5 \% \mathrm{RH}$. 


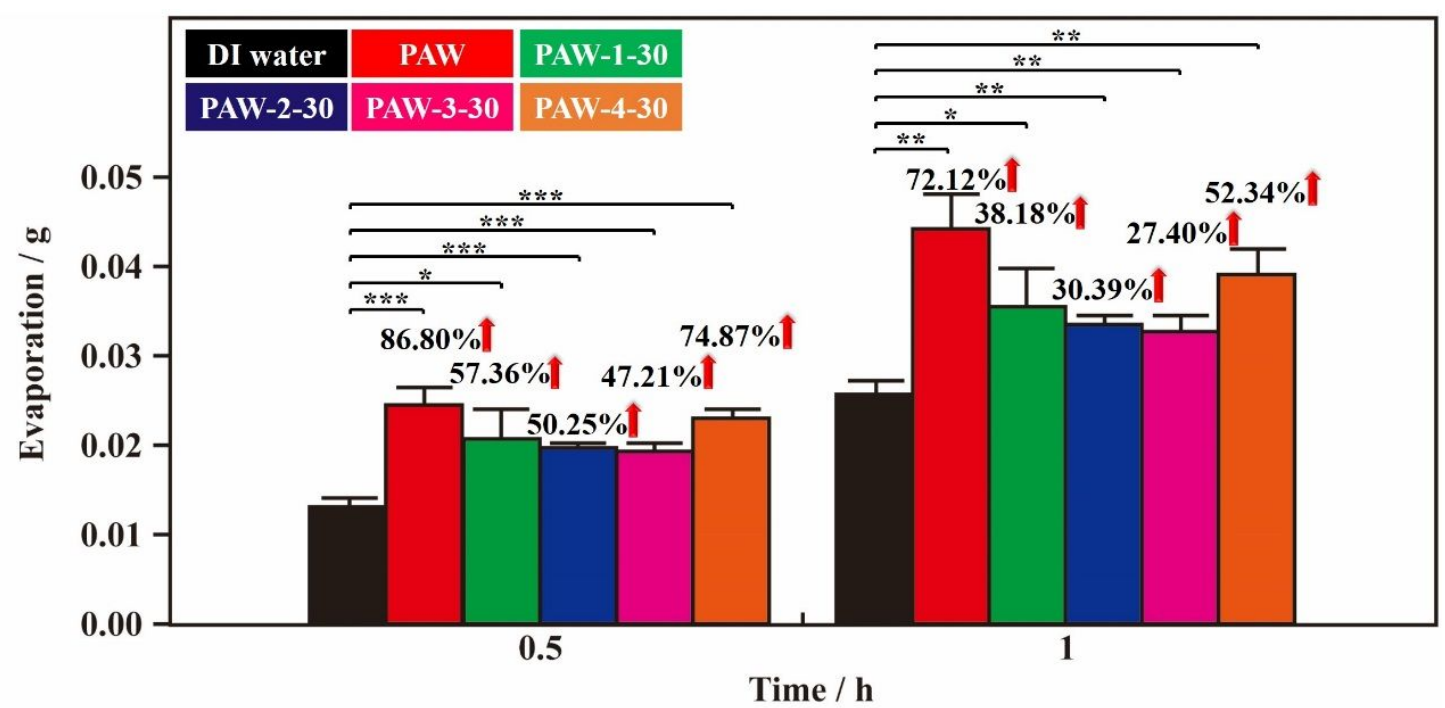

(A)

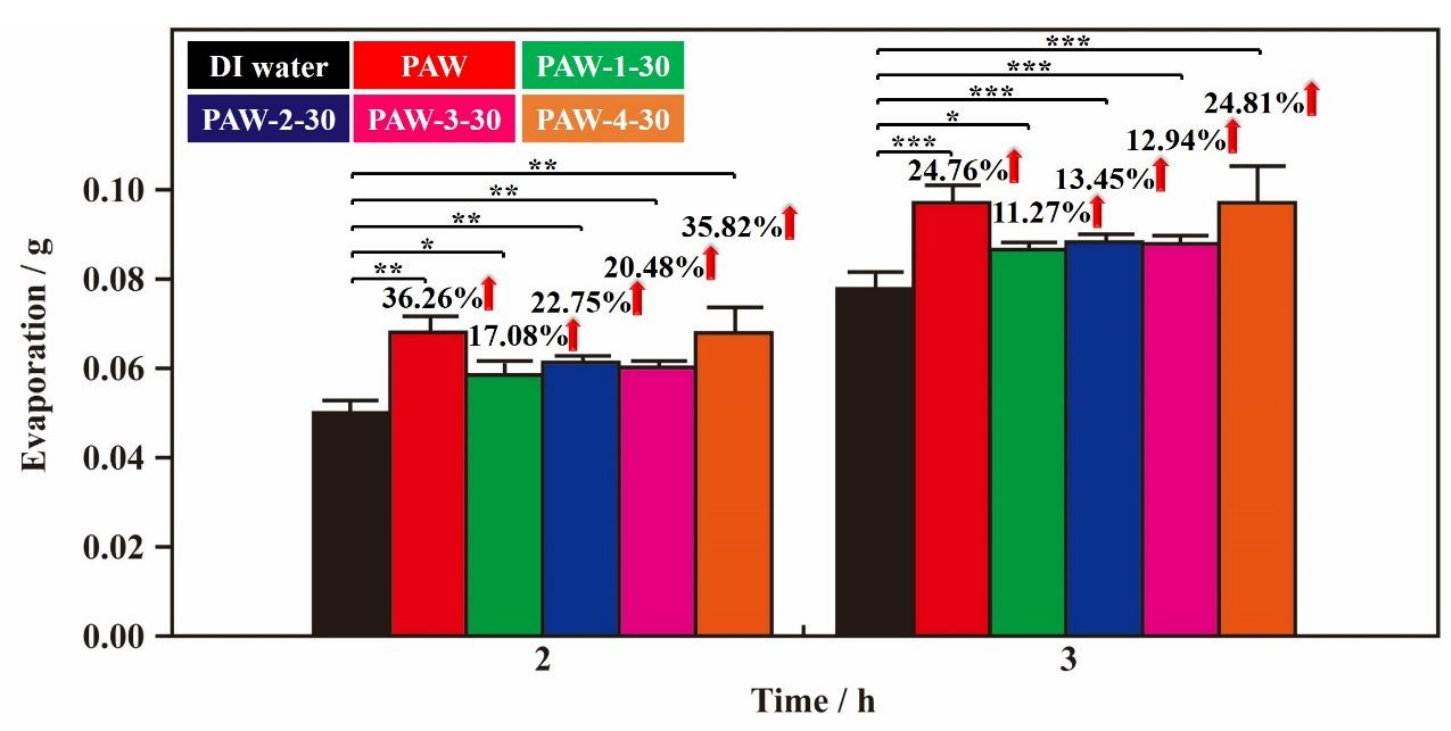

(B)

Figure S5. Evaporation quantities (g) with time of as-prepared plasmon-activated water (PAW; red), various 30-day-aged PAW, and deionized (DI) water (black) for reference. (A) At 0.5 and $1 \mathrm{~h}$ after the experiment began. (B) At 2 and $3 \mathrm{~h}$ after the experiment began. Green: slowly frozen/slowly melted PAW-1-30; blue: slowly frozen/rapidly melted PAW-2-30; pink: rapidly frozen/slowly melted PAW-3-30; orange: rapidly frozen/rapidly melted PAW-4-30. * $p<0.05 ; * * p<0.01 ; * * * p<0.001$. The evaporation experiments were performed at $1 \mathrm{~atm}, 24.0^{\circ} \mathrm{C}$, and $58.5 \% \mathrm{RH}$. 
